AsCLePIO. Revista de Historia de la Medicina y de la Ciencia

71(2), julio-diciembre 2019, p272

ISSN-L: 0210-4466

https://doi.org/10.3989/asclepio.2019.13

\title{
DOSSIER
}

\section{EXPEDIÇÕES CIENTÍFICAS E COLECIONISMO: DOIS EXEMPLOS NO BRASIL- SÉCULO XX}

\author{
Heloisa Maria Bertol Domingues \\ Museo de Astronomia e Ciências Afins (MAST/MCTIC) \\ Email: heloisa@mast.br \\ ORCID iD: http://orcid.org/0000-0001-5489-8299 \\ Magali Romero Sá \\ Fundaçâo Casa de Oswaldo Cruz (COC-Fiocruz) \\ Email: magalirsa@gmail.com \\ ORCID iD: http://orcid.org/0000-0002-5830-2525
}

Recibido:1 enero 2019; Aceptado: 20 Mayo 2019

Cómo citar este artículo: Domingues, Heloisa M. Bertol; Sá, Magali Romero (2019), "Expedições Científicas e Colecionismo: dois exemplos no Brasil-Século XX", Asclepio, 71(2): p272. https://doi.org/10.3989/asclepio.2019.13

RESUMO:Este trabalho analisará o significado das coleções reunidas em duas séries de expedições científicas realizadas no Brasil, desde o início até meados do século XX. Em primeiro lugar, trata-se de analisar as coleções reunidas durante a chamada Comissão Rondon, na verdade, várias expedições, realizadas entre 1907 e 1915, no início do período republicano no Brasil, período fortemente marcado pelo pensamento positivista. Tinha o objetivo de demarcar estações telegráficas, criando intercomunicação entre os diversos Estados do País e destes com a capital federal e ou o mundo. Em segundo lugar serão consideradas as expedições lideradas pelo antropólogo Luiz de Castro Faria, durante as décadas de 1940 e 1950, no litoral do país, desde o Rio Grande do Sul, até a Bahia. Nesta série, será considerada ainda a conhecida expedição à Serra do Norte, no Mato Grosso, em 1938, cujo chefe foi Claude Lévi-Straus e da qual Castro Faria participou como representante do Museu Nacional e do Conselho de Fiscalização das Expedições Artísticas e Científicas. As coleções reunidas em ambas as séries de expedições destinaram-se ao Museu Nacional do Rio de Janeiro.

PALAVRAS CHAVE: Coleções cientificas; Comissão Rondon; Mato Grosso; Castro Faria; Antropologia.

\section{SCIENTIFIC EXPEDITIONS AND COLLECTIONS: TWO EXAMPLES IN TWENTIETH CENTURY BRAZIL}

ABSTRACT:This work will analyze the meaning of the collections gathered in two series of scientific expeditions carried out in Brazil from the early to the mid-twentieth century. First, it will present the collections gathered during the so-called Rondon Commission, that comprises, in fact, several expeditions held between 1907 and 1915 at the beginning of the republican period in Brazil, a period strongly marked by positivist thinking. The main objective was to construct telegraph lines in order to create intercommunication between the various States of the country and these with the federal capital and or the world. Second, it will approach the expeditions led by the anthropologist Luiz de Castro Faria, during the 1940s and 1950s, along the coast of the country, from Rio Grande do Sul to Bahia. Also, will be considered in this series, the well-known expedition to the Serra do Norte, in Mato Grosso, in 1938, whose head was Claude Lévi-Straus and of which Castro Faria participated as representative of the National Museum and of the Council of Inspection of the Artistic and Scientific Expeditions. The collections assembled in both series of expeditions were destined for the National Museum of Rio de Janeiro.

KEY WORDS: Scientific collections; Rondon commission; Mato Grosso; Castro Faria; Anthropology.

Copyright: ( 2019 CSIC. This is an open-access article distributed under the terms of the Creative Commons Attribution 4.0 International (CC BY 4.0) License. 


\section{INTRODUÇÃO}

Este trabalho trata de duas expedições de ciências naturais no Brasil, que deram às coleções uma dimensão,além da científica, política e social, pois ao reunirem objetos da natureza 'brasileira' desbravaram o Brasil, mapeando-o. Comparadas às expedições que se realizaram desde o século XVIII e, principalmente, no século XIX, que tinham a finalidade de reunir coleções científicas como subsídio às ciências da natureza dentro de um processo de mundialização dos conhecimentos, as expedições analisadas nesse trabalho interpretam as coleções científicas como característica de um contexto localizado ${ }^{1}$.

Na América Latina, o Brasil foi um dos países pioneiros na criação de instituições de ciências naturais, como o Jardim Botânico, criado em 1808, e o Museu Nacional, criado em 1818, que foi por muito tempo o grande museu de ciências naturais da América do Sul. Nos 200 anos de sua existência, completados em 2018, reuniu uma enorme e importante coleção mundial de objetos da natureza. Ao mesmo tempo que comemorava o bicentenário, a tragédia de um incêndio de grandes proporções ocorrido em 02 de setembro deste mesmo ano destruiu cerca de 20 milhões de peças e documentação, a maior parte da sua preciosa coleção. O incêndio destruiu os objetos, porém não impedirá que se perca o significativo valor científico e social das ciências ali produzidas.

Este trabalho, como uma homenagem à instituição e um ato de preservação da memória daquela coleção, analisa as expedições chefiadas pelo Marechal Cândido Mariano da Silva Rondon e pelo antropólogo Luiz de Castro Faria, que reuniram coleções diferentes em número e em especialidades, com o objetivo, como se disse, de dar valor à cultura do País e à natureza brasileira. Essas expedições, diferentemente daquelas do século XIX, não se incluem no movimento de circulação internacional dos objetos naturais. Caracterizam-se pela representação de Brasil que carregavam. Ou seja, há um nacionalismo intrínseco aos objetos que coletaram e aos objetivos que as nortearam, embora tivessem pautado suas práticas a métodos e técnicas internacionais de pesquisa.

\section{DOIS MOMENTOS DO COLECIONISMO NA HISTÓRIA NATURAL DO BRASIL}

As pesquisas de campo determinaram a conformação e o crescimento das coleções de objetos naturais e permitiram desenvolver as tarefas, de um lado, dos museus de ciências naturais, de conservar e exibir; de outro, dos jardins botânicos, de aclimatar e difundir espécies pelo interior. Permitiram desenvolver as especialidades científicas respectivas, que ganharam projeção internacional. No século XIX, as coleções eram formadas preferencialmente por objetos materiais que representavam as diferentes especialidades das ciências naturais, e estas eram complementadas por desenhos que divulgavam as peças coletadas. No século $X X$, as expedições científicas e, consequentemente, a prática do colecionismo, ganharam um perfil diverso, no tocante à representação da natureza e à importância de objetos para incrementar coleções de museus ou herbários².

Há que se considerar ainda, que o movimento de autonomização das disciplinas, no século $X X$, redefiniu a estrutura das expedições e consequentemente $o$ perfil das coleções. Impôs a formação de equipes de especialistas para realizar as expedições, o que, por sua vez, concorreu para dividir as coleções resultantes de acordo com as diversas especialidades das ciências naturais. Ganharam força os laboratórios acadêmicos alterando também os lugares de guarda de coleções, até então assegurados apenas a museus e herbários. Essa mudança deu lugar à diversificação das coleções. Por exemplo, ao invés de animais, peles, moléculas, amostras de sangue; em lugar apenas das plantas, sementes, amostras de solo etc., como chama a atenção Strasser (2012). Ao mesmo tempo, a etnografia do século XIX transmudou-se na etnologia, voltando-se para o estudo das diferenças culturais dos habitantes do interior o que concorreu para transformar a antropologia em ciência social. Mudaram as questões que levavam os cientistas ao campo. Os museus já não eram simplesmente lugares de classificação e de exibição de objetos naturais; a pesquisa científica, incluindo o colecionismo, cresceu em várias direções visando, não somente à internacionalização, mas, também, a "internalização", como nos casos aqui descritos.

Os dois exemplos de expedições científicas analisados nesse trabalho mostram as mudança nas práticas das ciências naturais e nas formas do colecionismo, no Museu Nacional, dividido agora entre o material e o imaterial. O avanço tecnológico influenciou o colecionismo e, os desenhos, antes complementares à coleção de objetos, foram substituídos pelas imagens fotográficas que, paralelamente aos objetos, tornaram-se elas mesmas coleção. Porém, foram os objetivos do conhecimento que as identificaram e assina- 
laram a mudança radical na prática científica e na respectiva coleta de objetos naturais, pois era o conhecimento do "Brasil para o Brasil" que aquelas expedições buscavam. Essas expedições mostram dois momentos e duas visões da prática do colecionismo para museus de ciências naturais. Duas visões que não são excludentes mas que refletem as relações dos cientistas com as culturas locais, e com o trabalho de campo, cujas coleções revelam inquietações e questões que delimitavam o campo científico e o contexto social que viviam.

A discussão dessas duas visões de colecionismo contribuirá para ampliar o entendimento das expedições científicas, enquanto conhecimentos universais construídos sobre fatos localizados (Domingues, 2013, p. 101). Entre o local e o global, a análise dirá como historicamente as ciências naturais interpretaram a diversidade cultural e sua interconectividade. Mostrará, da mesma forma, o potencial científico do trabalho de campo evidenciado nas formas do colecionamento e no seu significado social, na medida em que, para esses cientistas, imbuídos dos mesmos princípios naturalistas, colecionar significava preservar além do objeto, ou da imagem, o ambiente e a diversidade de culturas que lhe deram origem e que viam como inerentes à sociedade "nacional".

\section{AS COLEÇÕES DE HISTÓRIA NATURAL DA COMISSÃO RONDON}

Em janeiro de 1915, o coronel Cândido Mariano da Silva Rondon (1865-1958) dava como finalizado um dos maiores empreendimentos realizados durante as primeiras décadas da jovem República brasileira, por ele chefiado. Conhecida como Comissão Rondon a "Comissão de Linhas Telegráficas Estratégicas de Mato Grosso ao Amazonas" (CLTEMTA), tinha a missão de expandir a infraestrutura de comunicações do país por meio do telégrafo. O governo brasileiro pretendia, assim, garantir a interiorização da presença do Estado brasileiro. Rondon foi escolhido para chefiar essa missão. Mato-grossense, de uma família de poucos recursos e órfão, Cândido Rondon encontrou na carreira militar uma perspectiva de futuro profissional. Aluno da Escola Militar da Praia Vermelha do Rio de Janeiro, tornou-se engenheiro militar e bacharel em matemática, ciências físicas e naturais em 1890. Na Escola Militar, foi também professor de astronomia e mecânica e aderiu ao positivismo que orientaria diversas de suas posições, como a visão benemérita e útil da ciência e a perspectiva protecionista e tutelar no tratamento da questão indígena. Suas atividades na construção de linhas telegráficas remontam ao início da carreira de oficial do Corpo de Engenharia Militar. Desde os anos 1880, ainda durante o Império, o batalhão de engenheiros do exército já vinha trabalhando na construção de estradas de ferro e linhas telegráficas. Com a República, foi criada a Comissão Construtora da Linha Telegráfica que ligaria Mato Grosso a Goiás e Rondon começou a atuar nesta comissão em 1891. Seus trabalhos estenderam-se até 1898, e, entre 1900 e 1906, Rondon ainda participou da construção da linha telegráfica entre Cuiabá e Corumbá (Sá et al., 2008).

A partir de 1907, Rondon e a equipe formada por um grupo de oficiais e praças do Exército brasileiro, telegrafistas e guarda-fios, civis contratados para trabalhos pesados, naturalistas e, eventualmente, grupos de indígenas, passaram a percorrer vastas regiões dos atuais estados brasileiros de Mato Grosso, Rondônia e Amazonas mapeando território, recolhendo espécimes da fauna e flora, contatando e revelando tribos indígenas e seus costumes.

A incorporação de naturalistas à Comissão de Construção das Linhas Telegráficas de Mato Grosso ao Amazonas atendeu às diretrizes ministeriais e veio ao encontro das necessidades prementes do Museu Nacional de aumentar a representatividade em sua coleção de exemplares da fauna e flora do interior do Brasil. João Batista de Lacerda, diretor do Museu Nacional à época, alertava as autoridades brasileiras para a necessidade de se adquirir novas coleções para a instituição associando o engrandecimento do Museu ao projeto de construção do País, assinalando que "se queremos tornar indiscutível a hegemonia do Brasil na América do Sul, devemos encarar essa política também do ponto de vista de superioridade dos nossos recursos intelectuais, e dos nossos institutos de ensino e de ciência" (Lacerda in Bicalho, 1946, p. 34).

O Museu Nacional foi convidado a participar da Comissão Rondon com o objetivo de inventariar e estudar a fauna e flora da região percorrida, assim como de ser o fiel depositário de todo o material de história natural, arqueologia e etnografia coletado. O objetivo era reunir o maior número possível de exemplares para a instituição. A iniciativa de reunir naturalistas para compor a Comissão com objetivo específico de coletar sistematicamente material para a instituição durante toda a jornada de trabalho de exploração, mapeamento e ocupação teve um significado altamente relevante 
para o conhecimento da história natural do país, tanto para o aumento da representatividade em suas coleções botânicas, zoológicas e etnográficas de exemplares coletados em lugares ainda não explorados, como para o fortalecimento e consolidação de carreiras científicas. Os trabalhos científicos da Comissão Rondon se diferenciaram em relevância e impacto de outras Comissões Científicas realizadas durante o Império e início da República ${ }^{3}$.

Para compor a comissão foram escolhidos o zoólogo Alípio de Miranda Ribeiro (1874-1939) e o jardineirochefe do Horto Botânico Frederico Carlos Hoehne. Do Serviço Geológico e Mineralógico do Brasil, foi enviado o engenheiro Cícero de Campos. Miranda Ribeiro ficou responsável pela orientação e comando dos naturalistas participantes da Comissão. Mineiro de Rio Preto, Miranda Ribeiro iniciou oficialmente seus trabalhos na instituição em 1894, durante a direção de Domingos Freire, como preparador interino de osteologia. Três anos depois, em 1897, foi efetivado por concurso como Naturalista Ajudante. Autodidata, reunia as habilidades de taxidermista, desenhista (inclusive na técnica de aquarela) e sagaz observador, qualidades essenciais para a coleta e preparação de objetos de história natural. De 1899 até o ano de sua convocação para compor a comissão, ele já tinha publicado 21 trabalhos sobre os mais variados grupos zoológicos, sendo que desde 1907 vinha desenvolvendo um dos seus mais relevantes projetos sobre a fauna brasileira de peixes: Fauna Braziliense - Peixes, com os tomos 1 e 2 já publicados (Sá, 2017).

Frederico Carlos Hoehne (1882-1959) havia acabado de ser contratado em 1907 para chefiar o Horto Botânico do Museu Nacional, quando recebeu convite para participar da Comissão Rondon. Filho de imigrantes alemães, Hoehne nasceu em Juiz de Fora e foi criado em área rural, nas imediações da cidade. Sua iniciação em botânica veio através de seu pai, que era proprietário de um orquidário, tendo Hoehne desde cedo se familiarizado com esse grupo botânico. Autodidata como Miranda Ribeiro, Hoehne já aos oito anos tinha sua própria coleção de orquídeas, tendo também formado através dos anos uma coleção de plantas diversificada, inclusive permutando com outros pesquisadores (Franco e Drummond, 2005).Assim, com apenas 25 anos, o jovem botânico teve a oportunidade de participar de um marcante empreendimento que o projetaria como um botânico profissional.

Os três pesquisadores partiram do Rio de Janeiro em direção a Mato Grosso em 27 de junho de 1908, carregando em sua bagagem todo o material neces- sário para a captura e acondicionamento de espécimes, que incluíam: lentes, lupa, termômetro, telas, lâmpadas apropriadas, vidrarias, material de desenho, pinças, estiletes, latões de cobre para acondicionamento de peixes, prensas para as coleções botânicas, torno de mão, tubos de vidro com rolhas, bússola de algibeira, barômetro, tela fina, pinças, tubos de vidro, tarrafas, espingardas, saco para capturar borboletas, caixas para acondicionamento de insetos dípteros e outras exclusivamente para mosquitos, alfinetes entomológicos etc., além de bibliografia especializada na história natural da região a visitar ${ }^{4}$.

Miranda Ribeiro e seus companheiros Cícero de Campos e Frederico Hoehne, ao chegarem a Mato Grosso dedicaram-se a coletar avidamente espécimes dos mais variados grupos zoológicos e botânicos, além de fósseis e material mineralógico.

Miranda Ribeiro, que tinha as atribuições de coletar, taxidermizar, desenhar e acondicionar o material coletado, reuniu todos os grupos zoológicos possíveis, desde mamíferos de pequeno e grande porte (roedores, macacos, morcegos), a aves, répteis e peixes, até diferentes tipos de invertebrados, como moluscos, crustáceos, insetos (que segundo ele, estavam sendo colecionados 'incontinentemente') a vermes (parasitários ou não). Aves, peixes e anfíbios eram os grupos que mais atraiam a atenção do pesquisador. Outros, como crocodilos, eram assinalados pela importância dos possíveis parasitos de que seriam portadores, como focos de "hematozoários perigosos". Os carnívoros e os pequenos roedores se apresentavam como os mais difíceis de observar e coletar, o que frustrava grandemente o zoólogo da expedição. Isto porque das mais de 60 espécies de ratos conhecidas no Brasil, todos os tipos se encontravam depositados em coleções de instituições de fora do país.

Miranda Ribeiro não atuava simplesmente como coletor e preparador. Seu entrosamento com as teorias evolucionistas da época levava-o a estabelecer questões, observar as inter-relações dos animais com o meio em que viviam, assim como fazer observações zoogeográficas, ecológicas e biológicas sobre os espécimes coletados. Antes mesmo de chegar à região, uma das questões que o preocupava dizia respeito à distribuição geográfica dos peixes e as comunicações possíveis das águas do Jaurú com as do Guaporé. Para ele a fauna fluvial do Paraguai, tinha suas comunicações com as do Amazonas, por intermédio dos banhados de origem do Guaporé, o que procurou comprovar através das espécies de peixes que vinha coletando ${ }^{5}$. 
Ao acompanhar Rondon na expedição ao Madeira, Miranda Ribeiro vislumbrou uma oportunidade única de desbravar uma região de mata virgem amazônica, ambição de todo naturalista, especialmente por contar com o apoio do aparato da Comissão das Linhas Telegráficas e por estar ao lado de Rondon quando dos primeiros contatos com sociedades indígenas. Não havia melhor oportunidade de vivenciar em toda a sua plenitude a sensação experimentada por um coletor de história natural nos trópicos. Tal romantismo, porém, foi aos poucos arrefecendo em virtude das agruras impostas pela natureza selvagem. Como relatado por Rondon (Viveiros, 1958, p. 294), em poucos meses a expedição já se encontrava em condições extremamente precárias; havia falta de provisões, os expedicionários resistiam retirando sua subsistência do alimento que podiam caçar e colher, como peixes, caça, mel e palmito. Com a chegada das chuvas o implacável ataque dos insetos e as febres acometiam a maioria dos expedicionários. Muitas coleções tiveram que ser deixadas para trás, inclusive registros fotográficos, experiência inovadora em excursões científicas à época.

Miranda Ribeiro de volta ao Rio de Janeiro passou a trabalhar o material coletado que havia sido enviado ao Museu Nacional, separando os diversos grupos e convidando especialistas brasileiros para trabalhar os diferentes grupos zoológicos da coleção reunida por ele, assim como o botânico Frederico Carlos Hoehne na organização da coleção botânica.

As excursões nos anos posteriores para conclusão da linha telegráfica não contou com a presença de Miranda Ribeiro que enviou taxidermistas auxiliares para coletar material zoológico. Em 1910 os irmãos Hermano Kuhlmann (guarda-fio de segunda classe dos telégrafos) e João Geraldo Kuhlmann acompanharam Hoehne. O primeiro foi incumbido de cuidar do rancho da tropa e foi treinado para realizar a taxidermia dos vertebrados coletados e o segundo a auxiliar nos serviços de herborização etc.

Hoehne chegou de volta ao Rio de Janeiro em abril de 1912, trazendo além do material zoológico e etnográfico, uma coleção botânica de mais de 1000 espécies num total de 4000 exemplares dos mais variados grupos da flora regional. O material etnográfico incluía peças das sociedades Mundurucú se Apiacás, que foi devidamente encaminhado ao etnógrafo do Museu Nacional, Edgard Roquette-Pinto.
Uma nova jornada iniciada em novembro de 1913, esteve associada diretamente ao Presidente dos Estados Unidos da América, Theodore Roosevelt, que, quando em visita ao Brasil naquele ano para realizar conferências, expressou desejo de explorar os sertões brasileiros até o Amazonas. Tal intenção foi prontamente apoiada pelo governo brasileiro, que através de Lauro Müller, Ministro do Exterior do Brasil, convocou Rondon para acompanhar Roosevelt na empreitada. Rondon sugeriu, então, que fizessem o reconhecimento do rio da Dúvida, já que não se sabia ao certo se ele desaguava no Ji-Paraná ou no Madeira.

Rondon convidou Hoehne e Miranda Ribeiro para participarem da comissão e coletarem material para o museu brasileiro. Miranda Ribeiro indicou os taxidermistas Arnaldo Blake de Sant'anna e Henrique Reinisch, que atuariam sob a orientação de Hoehne. A parte de geologia ficou a cargo do engenheiro Euzébio Paulo de Oliveira; Para a coleta de insetos foi enviado o médico de Saúde Pública Fernando Soledade. Além deles, fizeram parte da comitiva brasileira o médico Antônio José Cajazeira, e o desenhista e fotógrafo tenente Thomaz Reis.

A união das comissões científicas brasileira e americana acabou gerando tensão em função do tratamento diferenciado dado aos americanos e à falta de provisões e apoio para a comitiva brasileira. Tal situação fez com que, em apenas dois meses e quatro dias de expedição, em 23 de janeiro de 1914, fossem dispensados dos serviços da Comissão os naturalistas e auxiliares brasileiros (inclusive o fotógrafo), à exceção do geólogo e do taxidermista Reinisch, que daria prosseguimento à coleta de material zoológico.

Logo após o término da expedição com os americanos, Rondon retornou imediatamente para os seus afazeres junto à Comissão de Linhas Telegráficas, que continuava o serviço instalando novas estações nos rios Madeira e Jamari. Acompanhado do taxidermista Emil Stoll, Rondon inaugurou durante os oito meses seguintes cinco estações e construiu mais de 372.235 metros da linha. Desta forma, após anos de muito sofrimento transpondo com tenacidade incontáveis obstáculos e imprevistos inerentes à geografia e a natureza bruta da região percorrida, Rondon finalmente concluiu em janeiro de 1915 toda a extensão da linha telegráfica entre Cuiabá e Santo Antônio do Madeira (Sá et all, 2008).

As coleções científicas reunidas durante todos esses anos pelos pesquisadores e coletores, assim como por 
Rondon e pelos tenentes da Comissão, foram reunidas no Museu Nacional, onde começaram a ser trabalhadas pelos pesquisadores da instituição e do exterior ${ }^{6}$.

Para Edgard Roquette-Pinto, antropólogo do Museu Nacional que acompanhou Rondon em 1912 em uma das expedições à Serra do Norte, região compreendida entre os estados de Mato Grosso e Rondônia, "a construção da linha telegráfica foi o pretexto. A exploração científica foi tudo". Roquette Pinto participou da expedição imbuido de ideias nacionalistas e de integração das diferentes etnias que formavam a sociedade brasileira. Seu projeto científico, sobre os tipos [físicos] brasileiros, tinha a finalidade de dar a conhecer a formação da população do país, buscando afirmar a diferença física e a igualdade social.Voltou da viagem em 1913 com o esboço de Rondonia, livro baseado em seus diários de campo que publicaria em 1917 e que associa a descrição da vida indígena na região, sobretudo dos Nambiquara e Paresi, à das condições de vida e costumes dos sertanejos (Lima, 2005, p. 7). Marta Amoroso chama a atenção para o impacto que a expedição teve em Roquette-Pinto que retornou com "munição para empreender uma reviravolta nos debates sobre raça que se travavam no Brasil na primeira década do século XX". No I Congresso Brasileiro de Eugenia que presidiu em 1929, Roquette-Pinto defendeu o combate ao racismo no campo científico e no pensamento social, e de defesa da educação e da necessidade de atendimento À saúde como serviço garantido pelo Estado para a população indígena e sertaneja do interior do país (Amoroso, 2017, p. 186) .

Miranda Ribeiro em uma das conferências que proferiu sobre a Comissão comparou a formação das coleções de botânica, zoologia e antropologia nos quase 100 anos de existência da instituição, criada em 1818, em relação às contribuições enviadas pela Comissão do Mato Grosso ao Amazonas em apenas 8 anos, enfatizando a diversidade e o volume das médias anuais dos exemplares coletados. Em áreas como a botânica, a média anual da Comissão era de envio de 1104 exemplares enquanto a anterior era de 530 . Em zoologia, a média era de 709 contra os 593,14 anteriores. No caso da coleção antropológica, a diferença era ainda mais notável: 422 contra 11,85 (Ribeiro, 1945).

Miranda Ribeiro assinalava em seus relatórios que o trabalho científico da Comissão não resultou somente no expressivo aumento das coleções do Museu, mas sua relevância se dava principalmente com as novas descobertas de espécies de mamíferos, aves, insetos, plantas e substâncias vegetais medicinais, de peixes e algas de água doce, e com a divulgação nas publicações de suas respectivas figuras, ou em estampas, segundo ele, "belamente executadas", ou em fotografias, "muitas delas pela primeira vez tiradas em estado natural". Na área de botânica, as coleções teriam fornecido subsídios para as pesquisas de Alberto José de Sampaio, que preparou o trabalho $A$ Flora de Mato Grosso publicado no periódico da instituição os Arquivos do Museu Nacional (Ribeiro, 1945) e que evidenciava o quanto a expedição contribuía para o conhecimento da natureza do país.

O botânico Frederico Carlos Hoehne, que percorreu cerca de $7.350 \mathrm{~km}$ dos campos e das florestas do Mato Grosso para coleta de material botânico e observações fitofisionômicas. Comentaria anos depois na publicação "Índice Bibliográfico e Numérico das Plantas Colhidas pela Comissão Rondon" (1951):

para podermos avaliar o que representa, para a economia do País, o estudo da flora de Mato Grosso, precisaremos considerar que ele é o coração da América do Sul e, além disso, tão vasto que da sua superfície poderíamos recortar, comodamente, as equivalentes para reconstituir [....] a Alemanha, França e Itália e ainda obter retalhos bastantes para obter as superfícies para um Portugal, uma Holanda, sem esgotar tudo! Tão grande é Mato Grosso com o seu milhão e seiscentos mil quilômetros quadrados que, proporcionando de fato condições edafológicas, topográficas e climatéricas ótimas, poderia ser preparado para conter e nutrir 750.000 .000 de habitantes. [...]O Pantanal, preparado para a agricultura, nutriria a todos ${ }^{7}$.

Além do impacto positivo das coleções reunidas para o avanço do conhecimento da história natural da região central do Brasil, a Comissão Rondon exerceu notável influência na formação de novas gerações de antropólogos e etnógrafos brasileiros, entre os quais destacam-se nomes como os de Edgar Roquette-Pinto e Luiz de Castro Faria. Os esforços compreendidos por Rondon e pelos antropólogos que passaram a defender a causa indígena resultou na criação do Serviço de Proteção aos Índios em 1910 e na criação do Parque Nacional do Xingú, proposto por Rondon quando presidia o Conselho Nacional de Proteção aos Índios e por antropólogos e indigenistas, como os irmãos Villas-Boas. O Brasil Central anteriormente mapeado por Rondon passou a fazer parte do grande projeto de ocupação da região pelo governo Vargas com a criação da Fundação Brasil Central e a formação da expedição Roncador-Xingu que culminou com reconhecimento oficial das áreas ocupadas pelos povos indígenas (Maia, 2012). 


\section{A ETNOLOGIA NAS COLEÇÕES REUNIDAS POR LUIZ DE CASTRO FARIA}

Luiz de Castro Faria, foi antropólogo do Museu Nacional, onde ingressou em 1936 como pesquisador voluntário, visando a sua formação científica ${ }^{8}$. Em pouco tempo tornava-se naturalista sob a influência do pensamento de Raimundo Lopes, Heloisa Alberto Torres, Edgard Roquette Pinto; todos antropólogos identificados com a teoria de Franz Boas. Roquete Pinto, trabalhava principalmente com os métodos biológicos, Heloisa Alberto Torres dedicava-se à arqueologia e à etnologia. Raimundo Lopes foi um etnólogo excêntrico, avesso ao determinismo do meio, lançou-se à antropogeografia, inspirado na geografia humana francesa. Em seu livro intitulado Antropogeografia, publicado postumamente, em 1956, destacou o livro La Terre et l'évolution humaine, de Lucien Febvre, para quem aquela área nova da pesquisa geográfica resumia-se "na enorme questão das relações do solo e das sociedades humanas" (Domingues, 2010, p. 16) ${ }^{9}$. Esse viés teórico orientou Castro Faria.

O seu "batismo de fogo" científico aconteceu em 1938, quando, por indicação da diretora do Museu, Heloisa Alberto Torres, realizou o seu primeiro trabaIho de campo como integrante da conhecida expedição à Serra do Norte, chefiada por Claude LéviStrauss. Castro Faria participou desta expedição como antropólogo, representante do Museu Nacional e em missão oficial, de fiscal, do Conselho de Fiscalização das Expedições Artísticas e Científicas. Tal condição e o fato de Lévi-Strauss ter declarado que aquele trabalho de campo seria objeto de sua tese de doutorado inibiu-o, pois à época muito pouco analisou do rico material que reuniu durante a viagem - diários de campo, objetos etnográficos incluídos na coleção do Museu Nacional e uma imensa coleção de fotografias (Domingues, 2001, p. 13) ${ }^{10}$. Os diários de campo com as fotografias foram publicados sessenta anos depois, no livro Um outro olhar. Diário da Expedição à Serra do Norte, 1938 (Castro Faria, 2001). Este livro mostrou que a geografia do ambiente e a cultura social local constituiriam, desde então, no norte teórico do seu trabalho antropológico, assim como as notas de campo e os registros fotográficos seriam a sua base metodológica. Os objetos coletados em campo ganhavam valor museológico pelo significado sócio-histórico que lhe era atribuído.

No ano seguinte àquela expedição, 1939, realizou um segundo trabalho de campo, desta vez no Estado do Rio de Janeiro, ainda por solicitação da Diretora do Museu Nacional, com a finalidade de acompanhar o geógrafo americano William Lewis. O objetivo era percorrer 22 municípios por ele selecionados. Porém, não chegaram a percorrer todo o trajeto pois Lewis adoeceu e regressaram um mês depois de terem partido. Durante essa viagem, Castro Faria fez observações importantes sobre modos de socialização nas cidades, sobre as relações econômicas no meio urbano, distinguindo o mais industrializado daquele mais ligado à vida rural. Retornou com o projeto de estudar mais profundamente o Estado do Rio de Janeiro, a começar pelo Norte do Estado, onde coincidentemente havia nascido ${ }^{11}$.

Nos vinte anos seguintes realizou vários trabalhos de campo pelo litoral do País; do Rio Grande do Sul à Bahia, com incursões no Mato Grosso e em Minas Gerais. Inspirado na viagem de 1939, apresentou um projeto de pesquisa à direção do Museu com o objetivo de estudar etnologia e geografia humana no Estado do Rio Janeiro. Seria um estudo ecológico. O trabalho iniciou em meados de 1940. Com o mesmo objetivo realizou expedições no Espírito Santo e na Bahia, além do Estado do Rio. No litoral sul, nos Estados de Santa Catarina, Paraná e Rio Grande do Sul, onde fez a primeira expedição em 1947 , priorizou o trabalho arqueológico, particularmente, o estudo dos sambaquis.

Se possível fosse dividir o caráter de colecionismo no trabalho de Castro Faria este teria duas linhas. Uma linha etnológica, em que reuniu objetos e imagens representativas das relações sócio-econômicas estabelecidas em cada lugar pesquisado e uma linha arqueológica, em que deu destaque ao material lítico, obtido nas escavações que organizou ou simplesmente participou e à arquitetura urbana e rural, num esforço de valorização do que era classificado como patrimônio histórico, entendendo as edificações como lugares da socialização. Ambas identificavam o seu modo de fazer Antropologia. A coleção fotográfica que reuniu, como uma ferramenta fundamental da pesquisa, evidenciou que o seu objetivo central era o conhecimento das manifestações e relações culturais da sociedade brasileira, na sua diversidade histórica e geográfica.

Nas expedições que realizou a Campos - Lagoa Feia (1940), São João da Barra - Ilha da Convivência, Gargaú, (1940), Santa Maria Madalena, Macaé (1942), São João da Barra, Espírito Santo (1945), São João da Barra, Campos (1948) Arraial do Cabo (1953), Bahia (1949) -orientou as pesquisas e observações por 
questões científicas precisas, que definiram as formas de coletar objetos e de retratar os fatos. Em lugares lacustres e ilhas o estudo da pesca foi privilegiado. Em seus diários anotava as formas de organização do trabalho da pesca nos diferentes lugares e diferentes ambientes: lagos, rios ou mar, tratando da hierarquia dos pescadores embarcados ${ }^{12}$. Observava e descrevia como se realizava a divisão dos ganhos da pesca ou assinalava o quão importante era para os pescadores obedecer ao calendário da pesca, que determinava a época do ano que poderiam pescar sem intervir no processo de reprodução do peixe e consequentemente na preservação da espécie. Fotografava-os em ação, mostrando a diversidade de instrumentos, correspondentes a cada tipo de peixe. Fazia-o num momento em que no âmbito político do País, discutia-se a implantação da legislação trabalhista.

Em Gargaú, Estado do Rio de Janeiro, iniciou a pesquisa sobre relações comerciais, estudando as feiras e concluiu:

É o ponto de encontro de várias especializações. Pescador branco, afeito ao mar, usando apetrechos e empregando redes cuja origem constitui uma tradição, tão forte como a que o leva a dividir quinhões e a manter tão serena constância à profissão que herdaram. Negros que sempre amanharam a terra e ainda hoje fazem roças, plantam mandioca, usam tipiti - e preparam uma tapioca alva como neve. Carreiros e tropeiros brancos e mulatos; prancheiros brancos, queimados do sol. Gente que navega, gente que conduz tropas. Gente que um dia por semana confraterniza ali na feira ..."13.

Em 1949, realizou uma expedição à Bahia com o objetivo precípuo de estudar feiras em diversas cidades: Salvador, onde visitou a conhecida feira Água de Meninos e a feira da Penitenciária; Jacobina, Ilheus, Feira de Santana. Foi um amplo estudo de antropologia econômica. A coleção de objetos do cotidiano, que levou para o Museu destas viagens, adquiriu nos mercados locais ou nas feiras - colheres de pau, cestas, amostras de plantas medicinais, vasos, bilhas e pratos de cerâmica, vassouras, rolos de fumo, cachimbos ...

Da mesma forma, a preservação do patrimônio histórico, cultural e social, material e imaterial, foi uma meta constante dos estudos de Castro Faria. Nesse sentido realizou trabalhos de campo não somente para o Museu Nacional, mas também para o Instituto de Patrimônio Histórico e Artístico Nacional - em 1941, no Estado do Mato Grosso e em 1945 no Espírito Santo. Quando, em 1947, iniciou seus estudos sobre os sambaquis, no sul do Brasil, em Santa Cata- rina, engajou-se ardorosamente na campanha de proteção dos mesmos, tendo colaborado para a elaboração da respectiva Lei de Proteção aos Sambaquis, que entrou em vigor somente em 1961. Sobre os objetos que pode colecionar nestes sítios, deu destaque aos crâneos e esqueletos encontrados nos sambaquis de Santa Catarina, pois o número obtido mais do que dobrou a coleção que o Museu possuía até então, provenientes ainda das coleções do século XIX, feitas por João Batista de Lacerda ${ }^{14}$.

Quando em 1947, na sua primeira expedição à Santa Catarina e Paraná, engajou-se no estudo dos sambaquis, a comunidade de arqueologia internacionalmente ainda discutia a origem humana daqueles montes de conchas. Castro Faria entrou no debate e obteve respostas positivas a seus estudos e imediatamente abraçou o movimento de preservação dos sambaquis, como forma de preservação da cultura indígena original do País. Neste movimento reuniu-se aos arqueólogos, Loureiro Fernandes do Paraná, Padre Rohr de Santa Catarina, Paulo Duarte de São Paulo. Em Santa Catarina, a especulação imobiliária e a abertura de estradas por todos os lugares estava destruindo os sambaquis para aproveitar o cálcio das conchas e para pavimentar estradas. Destruíam, conforme observou em seus diários de campo, cemitérios, abrigos e restos de cozinha fossilizados e sobretudo seus próprios ancestrais. Nestes lugares encontrou inúmeros fósseis humanos e objetos líticos, como machados de pedra (um deles guardava sobre sua mesa de trabalho), adornos, restos de cozinha, inclusive fogões, que enriqueceram a coleção de arqueologia do Museu Nacional.

Para o conhecimento do sítio arqueológico o registro fotográfico surgiu para Castro Faria como instrumento indispensável. A escavação arqueológica é uma desconstrução. -“Não é possível descobrir o que esconde um sítio pré-histórico, a não ser desmontando-o lentamente até encontrar o solo natural, sobre o qual repousam as camadas artificiais, vestígios da atividade humana". Todos os passos do processo de desconstrução do sítio deveriam ser fotografados; desde as superfícies dos planos de escavação até que aflorassem todos os sinais de ocupação humana, pois representam o texto a ser lido e interpretado. Logo, "a pesquisa arqueológica não pode ser reduzida a uma simples coleta de objetos" (Castro Faria, 1998, p. 165). Embora o contexto fosse constituído pelos dados coletados, tais como esqueletos, artefatos ou qualquer evidência de atividade humana, também 
indispensáveis à apresentação de resultados científicos de uma escavação,"a fotografia é o único registro daquele contexto". Foi este trabalho meticuloso que realizou e durou até os anos 1960, nos sambaquis do Paraná e de Santa Catarina, dos quais o maior e mais importante foi o estudo do sambaqui da Cabeçuda.

Da mesma forma, os enterramentos, identificados por blocos de pedra, arranjados de maneira a cobrir um esqueleto, teriam a evidência do registro material mantida somente pela fotografia, pois a "tumba" tinha de ser destruída. -“Foi preciso desconstruir para erigir um saber novo". Aquela desconstrução era sempre complementada com a descrição, registrada no diário de campo. Ou seja, a imagem, ou uma série de imagens, mais do que uma simples ilustração, representava um instante a ser preservado.

Do Rio à Bahia - pode-se pensar em outra série de expedições - priorizou estudos de antropologia ecológica e econômica, observou e analisou os modos de vida e a economia. Sendo o objetivo central do seus estudos o conhecimento do cotidiano das populações do interior e da sua cultura social e econômica, as coleções que Castro Faria reuniu diziam respeito a esses objetivos e, embora conhecido por não ter enriquecido significativamente a seção etnográfica do Museu Nacional, os objetos que coletou foram representações importantes das culturas locais, com destaque a cestarias, cerâmicas, adornos, algumas armas e instrumentos de pesca.

Por outro lado, é preciso considerar que Castro Faria valorizou mais do que o objeto, a sua representação fotográfica, que lhe permitia reter em imagem o objeto geograficamente localizado. As fotografias foram, no seu trabalho, indubitavelmente, coleção e como tal devem ser entendidas. Usou a máquina fotográfica como instrumento de coleta [de imagens], desde os primeiros trabalhos de campo. Assim fazendo delimitou uma visão muito própria da prática científica e de coleção etnológica, incluindo-se numa abordagem teórica que classificou de antropologia ecológica. Tal abordagem parecia unir pela cultura social as duas antropologias - as chamadas antropologia física ou biológica e a antropologia cultural ou etnologia (Castro Faria, 2006, p. 37). Sem determinismos; relações sociais, saberes, ritos, trabalho foram reconhecidos como contingentes à exploração do meio ${ }^{15}$.

Logo, considerando a condição do meio relativa aos modos de vida, para Castro Faria objetos, fotografias e anotações de campo eram indissociáveis para a análise antropológica. Na primeira viagem, em 1938, colecionou tecidos, cestarias, objetos cerâmicos, algumas flechas e objetos de látex, esses obtidos na região de produção da borracha, para o Museu Nacional. Ao mesmo tempo, numa passagem da viagem, fotografou o gesto do índio atraindo a caça. $O$ índio usava os dedos para imitar a voz de uma ave. Em 1998, escreveu sobre essa foto: -“Ato fugaz que transformava os dedos e o sopro entre eles em instrumento que assegurava o êxito da caçada". Um gesto passível de registro somente pela imagem. Concluiu então: - "somente a fotografia podia proporcionar ao antropólogo em campo a possibilidade de fixar numa imagem um ato que não envolve o uso de um objeto que o representa, e de que a linguagem, no melhor de sua expressividade escrita, não daria conta" (Castro Faria, 1998, p. 167).

Figura 1. Foto Luiz de Castro Faria, Arquivo Museu de Astronomia e Ciências Afins - MAST

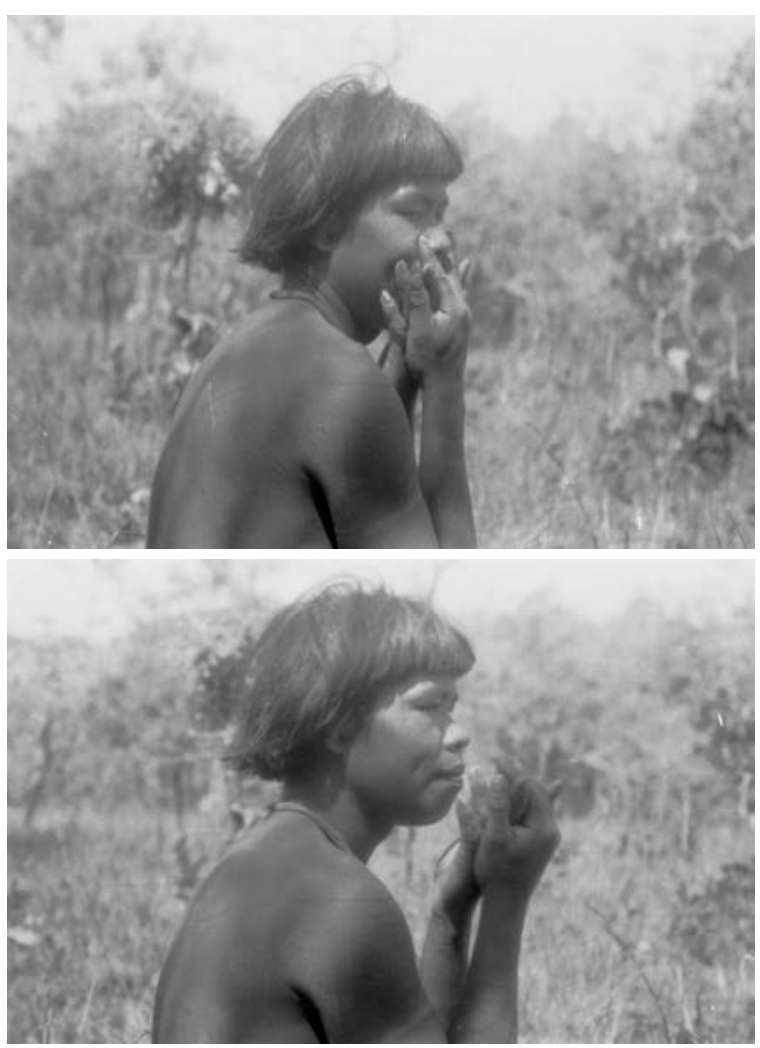

Em sua tese, de 1943 - Origens Culturais da Habitação Popular no Brasil ${ }^{16}$-destacou, os processos de construção das casas, isto é, a arquitetura popular, de diferentes lugares. A esta chamou de "um saber prático", porque embora dispensassem profissionais da arquitetura, empregavam técnicas sofisticadas no 
processo de construção, que exigiam uma variedade de saberes, tais como, conhecimentos botânicos sobre: a qualidade das madeiras ou dos cipós mais convenientes para as amarrações; das palhas para a obtenção de uma cobertura eficaz e durável; da geologia de barros para obtenção das argilas; além de conhecimentos topográficos e métricos que permitiam acertar a localização e proporções em termos de espaços internos. Os passos da construção eram registrados por fotos sequenciadas, desde a estrutura até o acabamento da casa, o que permitia-lhe documentar as técnicas, os momentos da construção e os movimentos dos construtores em ação.

O uso da fotografia na antropologia não foi uma originalidade somente da sua prática; a máquina fotográfica acompanhava os antropólogos daquela época, como os desenhistas acompanharam os naturalistas no século XIX. Como o próprio Castro Faria observou, a câmera estava sempre à mão para reforçar a observação. Foi assim com Branislaw Malinovski, que consagrou o seu estudo no livro Os argonautas do Pacífico usando muitas fotografias, ou com Lévi-Strauss, que ele acompanhou à Serra do Norte ${ }^{17}$. Foi assim também com o antropólogo Roquette Pinto, que fez parte da Comissão Rondon, em 1912, e coletou objetos e também fotografias. O livro Rondônia, resultante do trabalho de Roquette Pinto naquela viagem, orientou Castro Faria na primeira expedição (Garcia e Sora, 2001, PP. 22-27).

Colecionar objetos pode não ter sido a prioridade do trabalho de campo de Castro Faria, no entanto, os objetos coletados, enquanto representação da diversidade da cultura social, valorizou-os como poucos. Ficavam para trás as instruções etnográficas de Paul Broca, da Sociedade de Antropologia, de Paris, que haviam dominado a metodologia do colecionamento no século XIX (Puig-Samper, 1988, p. 431; 2013, p. 71). Quanto às imagens, importava-Ihe colecionar, pois guardavam o gesto, o movimento, o fortuito, o efêmero, o que brevemente poderia ser destruído, explicou ele, em 1998, falando do sentido da fotografia para o seu trabalho antropológico (Castro Faria, 1998, p. 164).

Seus registros, nas muitas séries fotográficas, valorizaram o conhecimento tradicional destacando, conforme dito acima, formas de pesca e de caça, tecelagem, uso de vegetais no preparo de venenos (uma especialidade indígena), vestimentas, alimentos e tecnologias, como por exemplo, o equipamento para o preparo de farinha de mandioca ou do preparo do látex para a exportação, dos fornos de cozimento das cerâmicas. Destacou com ênfase os conhecimentos botânicos que permitiam aos índios distinguir venenos de alimentos ou medicamentos; permitiam-lhes ainda construir embarcações robustas, para percorrer os caminhos fluviais ou construir suas casas.

É indubitável, portanto, que o conjunto fotográfico resultante da prática antropológica de Castro Faria, constituiu uma coleção científica de importância inquestionável para a antropologia e torna-se ainda mais significativa após a tragédia que se abateu sobre o Museu Nacional, pois mantém o rastro documental. A coleção que ele deixou representou o material e imaterial e cumpriu o seu objetivo de conhecer o Brasil na sua diversidade.

Em 1953, anotou num caderno de notas:

\section{Cultura Brasileira}

Podemos admitir e aceitar como legítimas e válidas nas suas linhas, todas as tentativas de caracterização da cultura brasileira como definição de uma unidade que se afirma politicamente ou nacionalmente. Admitir que a essa cultura, que assim se define e caracteriza, corresponde uma unidade geral de traços e de complexos, uma unidade em todos os planos, seria simplesmente absur$\mathrm{do}^{18}$.

\section{CONSIDERAÇÕES FINAIS}

Como conclusão restam-nos perguntas: Entre o século $X I X$ e o século $X X$, o que é o colecionismo? $O$ que o colecionismo representou para as ciências? Que repercussão tiveram as coleções de objetos naturais e etnológicos com a sua exibição/divulgação na sociedade? O que dizer dos objetos hoje queimados do Museu Nacional?

No século XIX o colecionismo das expedições científicas com a exibição e estudos em museus, jardins botânicos, sociedades científicas e outras instituições atendeu a demandas da colonização da terra, numa simbiose ciência e sociedade. No século XX, os estudos científicos do meio, da cultura e dos recursos naturais, materiais, vêm enfrentando questões como o esgotamento do solo, a extinção das espécies nativas, de uso social e econômico e, na contramão, da intervenção maciça de espécies alienígenas, animais e vegetais, com todas as consequências que trazem para o meio e para as culturas e economias tradicionais, pondo em xeque o colecionismo e mudando as suas formas e objetivos. 
As expedições aqui analisadas tiveram a originalidade comum da ênfase na biogeografia e na geografia humana, quando a ecologia era uma ciência que apenas começava a se afirmar. Apoiavam-se num sentimento nacionalista que valorizava a história, a diversidade cultural e a biodiversidade da natureza. Coleções de objetos e de representações eram contextualizadas e compreendidas pelo valor social e científico que carregavam e como tal eram entendidas como objetos do museu de ciências naturais, como eixo de relações científicas internacionais e de relações políticas e sociais nacionais.

\section{NOTAS}

1. Sobre a institucionalização das ciências naturais desde o século XVIII e o processo de mundialização dos conhecimentos: Strasser(2012, p. 303); Lafuente y Oncón (2012); Losada; Puig-Samper y Domingues (2013). Sobre a ciência local ver Figueirôa (1998).

2. Conforme Strasser (2012), começaram a surgir os primeiros biobancos (como as coleções de moléculas), mas estes fogem ao escopo deste trabalho.

3. Comissão Geológica do Império (1875 - 1878); Comissão Exploradora do Planalto Central do Brasil (1892-1893; 1894-1896). Ver Freitas (2001); Figueirôa (1994); Vergara (2006).

4. Ofício de 26 de junho de 1908 , do diretor do Museu Nacional, João Batista de Lacerda, "atendendo a que estes objetos ficarão sob a guarda do empregado do Museu, em comissão do Ministério da Viação, Alípio de Miranda Ribeiro, e considerando que os trabalhos do comissionado reverterão em benefício do Museu, autorizo a entrega sob responsabilidade". Arquivo Histórico do Museu Nacional.

5. Ver Relatório apresentado à Diretoria Geral dos Telégrafos e à Divisão Geral de Engenharia do Departamento da Guerra pelo Coronel Cândido Mariano da Silva Rondon (chefe da Comissão): $1^{\circ}$ volume - Estudos e Reconhecimentos, s.d.

6. Infelizmente, todas as peças dessas coleções, como as demais do Museu Nacional, foram queimadas em incêndio de grandes proporções ocorrido na instituição em 02 de setembro de 2018. O incêndio atingiu as coleções etnográficas, antropológicas, entomológicas, malacológicas, aracnológicas, e praticamente todo o material em exposição.

7. Hoehne, Frederico Carlos. Índice bibliográfico e numérico das plantas colhidas pela Comissão Rondon ou Comissão de Linhas Telegráficas. São Paulo: Secretaria de Agricultura de São Paulo, 1951.
Os objetos queimados do Museu Nacional ficarão como memória de uma natureza hoje em risco.

\section{AGRADECIMENTOS}

Trabajo realizado en el proyecto de investigación: "El coleccionismo científico y las representaciones museográficas de la Naturaleza y de la Humanidad", financiado por la Agencia Estatal de Investigación del Gobierno de España y el Fondo Europeo de Desarrollo regional (HAR2016-75331-P.AEI/FEDER, UE).

8. Em 1943, prestou concurso, com uma tese sobre habitação popular no Brasil, e foi oficialmente nomeado naturalista do Museu Nacional. Foi também professor, por mais de 60 anos, nos cursos de pós-graduação do Museu Nacional e nos cursos de graduação, na Universidade Federal Fluminense, onde foi professor por 50 anos. Publicou vários livros e muitos artigos que Ihe deram notoriedade e reconhecimento científico no país e exterior. Foi chefe do Setor de Antropologia do Museu Nacional em mais de um mandato e Diretor da mesma instituição, entre 1964 e 1967. Em 2000, recebeu a medalha de Gran Cruz do Mérito Científico, do Presidente da República Brasileira.

9. A primeira edição do livro de L. Febvre é de 1922 (Paris, Albin Michel).

10. Para Lévi-Strauss esta viagem deu origem a Tristes Trópicos.

11. Nasceu em São João da Barra, em 1913.

12. Escreveu em seu diário de 1940: "O mestre rema na popa e dá o lanço; um camarada bota o chumbeiro (chumbeiro) e o outro pega no calão (caloeiro)."

13. Relatório de viagem, Arquivo MAST.

14. Relatório CNPq, Processo n. 493/D51. Arquivo MAST.

15. Luiz de Castro Faria, A ecologia do Chapadão Matogrossense. Palestra à Sociedade de Geografia, 1946. Documento do Arquivo Castro Faria, MAST. Nesta palestra Castro Faria sublinhou que o meio não é determinante da sobrevivência, portanto não se poderia falar em determinismo do meio sobre a cultura social.

16. Publicada no Boletim do Museu Nacional em 1951 (série Antropologia, n. 12).

17. Sobre a importância da fotografia para o trabalho antropológico e no trabalho de Castro Faria ver Patrícia MonteMor (2001), p. 28-31.

18. Castro Faria, Caderno de Notas, 1953. Arquivo MAST. 


\section{BIBLIOGRAFÍA}

Amoroso, Marta (2017), "Intenção de Arquivo: o invento etnográfico na Comissão Rondon". In Kury, Lorelai e Sá, Magali Romero (orgs.), Rondon: inventários do Brasil. Rio de Janeiro, Andrea Jakobsson Estúdio, pp. 174-195.

Bicalho, Magdalena de Lacerda (1946), "A personalidade de João Batista de Lacerda". In: João Batista de Lacerda: comemoração do centenário de nascimento, 1846-1946. Rio de Janeiro, Museu Nacional.

Castro Faria, Luiz de (1998), “O Antropólogo e a Fotografia: um Depoimento". In: Revista do Patrimônio Histórico e Artístico Nacional, 27, pp. 162-169.

Castro Faria, Luiz de (2001), Umoutro Olhar. Diário da Expedição à Serra do Norte, Mato Grosso, Rio de Janeiro, Editora Ouro Sobre Azul.

Castro Faria, Luiz de (2006), Antropologia: Duas Ciências. Almeida, Alfredo Wagner B. de e Domingues, Heloisa M. Bertol (orgs.), Brasília, CNPq, Rio de Janeiro, MAST.

Domingues, Heloisa M. Bertol (2001), "A última expedição etnográfica do século XX". In: Castro Faria, Luiz de (2001), Umo utro Olhar. Diário da Expedição à Serra do Norte, Mato Grosso, Rio de Janeiro, Editora Ouro Sobre Azul, pp. 13-21.

Domingues, Heloisa M. Bertol (2013), “Expedições científicas no Brasil: circulação de conhecimentos "internacionais" e de objetos "locais" (Séc. XIX)". In: Losada, Janaina, Z.; PuigSamper, Miguel Ángel; Domingues, Heloisa M. Bertol, (eds.), Um album para o Imperador: a Comissão Científica do $\mathrm{Pa}$ cífico e o Brasil,Uberlândia, EDUFU, pp. 101-124.

Domingues, Heloisa M. Bertol e Almeida, Alfredo Wagner B. de (Organizadores) (2010), Raimundo Lopes: dois estudos resgatados, Rio de Janeiro, Ed. Ouro Sobre Azul.

Figueirôa, Silvia Fernanda de Mendonça (1994), "Charles Frederic Hartt and the Geological Commission of Brazil (18751877)", Earth Sciences History, 13(2), pp.168-173.

Figueirôa, Silvia Fernanda de Mendonça (1998), “Mundialização das Ciências e Respostas Locais: sobre a institucionalização das ciências naturais no Brasil (de fins do século XVIII a transição ao século XX)", Asclepio, 50 (2), pp. 107-123.

Franco, José Luiz de Andrade; Drummond, José Augusto (2005), "Frederico Carlos Hoehne: a atualidade de um pioneiro no campo da proteção à natureza no Brasil", Ambiente \& Sociedade, 8 (1), pp.141-166.

Freitas, Marcus Vinicius de (2001), Hartt: expedições pelo Brasil imperial (1865-1878), São Paulo, Metalivros.

Garcia, Afranio; Sora, Gustavo (2001), “Castro Faria: A Experiência de Rondônia e a Antropologia no Brasil". In: Castro Faria, Luiz de, (ed.), Umo utro Olhar. Diário da Expedição à Serra do Norte, Mato Grosso, Rio de Janeiro, Editora Ouro Sobre Azul, pp. 22-27.

Hoehne, Frederico Carlos (1951), Índice bibliográfico e numérico das plantas colhidas pela Comissão Rondon ou Comissão de Linhas Telegráficas, São Paulo, Secretaria de Agricultura de São Paulo.
Lafuente, Antonio; López Oncón, Leoncio (2012), “Tradiciones científicas y expediciones ilustradas en la América hispana del siglo XVIII". In: Lafuente, A., Las dos orillas de la ciencia: la traza pública e imperial de la llustración española. Madrid, Fundación Jorge Juan - Marcial Pons, pp. 77-99.

Lima, Antonio Carlos de Souza (2005), “Apresentação”. In: Roquette-Pinto, Edgard, (ed.), Rondonia: anthropologia - ethnographia. 7. ed. Rio de Janeiro, Editora Fiocruz.

Losada, Janaina Z.; Puig-Samper, Miguel Ángel; Domingues, Heloisa M. Bertol (2013),Um album para o Imperador: a Comissão Científica do Pacífico e o Brasil, Uberlândia, EDUFU.

Maia, João Marcelo Ehlert (2012), Estado, Território e Imaginação Social: o caso da Fundação Brasil Central, Rio de Janeiro, Editora da Fundação Getúlio Vargas.

Monte-Mor, Patrícia (2001), “A importância da fotografia na pesquisa antropológica: A propósito das imagens de Castro Faria”. In: Castro Faria, Luiz de, (ed.), Um outro Olhar. Diário da Expedição à Serra do Norte, Mato Grosso, Rio de Janeiro, Editora Ouro Sobre Azul, pp. 28-31.

Puig-Samper, Miguel Ángel (1988), Crónica de una expedición romántica al Nuevo Mundo, Madrid, CSIC.

Puig-Samper, Miguel Ángel (2013), “A Comissão Científica do Pacífico no Brasil e o Presente fotográfico para Pedro II". In: Losada, Janaina Z.; Puig-Samper, Miguel Ángel; Domingues, Heloisa M. Bertol, (eds.), Um album para o Imperador: a Comissão Científica do Pacífico e o Brasil, Uberlândia, EDUFU, pp. 67-100.

Ribeiro, Alípio de Miranda (1945), A Comissão Rondon e o Museu Nacional (conferências realizadas pelo professor Alípio de Miranda Ribeiro no Museu Nacional em 1916), Rio de Janeiro, Papelaria Macedo.

Strasser, Bruno J. (2012), "Collecting Nature: Practices, Styles and Narratives". In: Kohler, Robert E.; Olesko, Kathryn M. (eds.), Clio Meets Science, Osiris (27), pp. 303-340.

Sá, Dominichi Miranda; Sá, Magali Romero; Lima, Nísia Trindade (2008), "Telégrafos e inventário do território no Brasil: as atividades científicas da Comissão Rondon (1907-1915)", História, Ciência, Saúde - Manguinhos, 15 (3), pp. 779-810.

Sá, Magali Romero (2017), "Um inventário dos sertões brasileiros. A exploração científica da Comissão Rondon". In: Kury, Lorelai; Sá, Magali Romero (eds), Rondon Inventários do Brasil 1900-1930, Rio de Janeiro, Andrea Jakobsson Estúdio Ltda, pp. 112-143.

Vergara, Moema de Rezende (2006), “Ciência e história no Relatório da Comissão Exploradora do Planalto Central na Primeira República", História, Ciências, Saúde-Manguinhos, 13 (4), pp.909-925.

Viveiros, Esther (1958), Rondon conta sua vida. Rio de Janeiro, Livraria São José. 